\title{
Research on Design Strategy of Green Building of University Gymnasium in Cold Areas
}

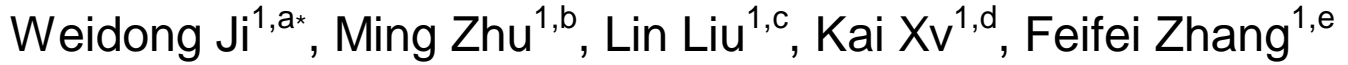 \\ ${ }^{1}$ Shandong Jianzhu University School of Architecture and Urban Planning, Jinan, China \\ a13808931960@163.com, b814813935@qq.com
}

\section{Keywords: Cold Area, University Gymnasium, Green and Low-carbon, Ecological and Energy-saving}

Abstract. Green building will be developed towards the direction of low energy consumption, high efficiency and less pollution. This paper is focused on the analysis of design process and application of ecological and energy-saving technique of the gymnasium of Weifang Medical University, with a view to discussing the green, low-carbon and energy-saving design strategy of university gymnasium in cold area.

\section{Introduction}

Within the scope of university sports building, university gymnasium is mainly used for teaching and sports as well as the activities such as campus competitions, artistic performance and public gathering. It is not only a physical carrier for the connotation of sports cultural movements and social cultural mentality but also the carrier of science \& technology and ecology.

Buildings should be adaptive and regional in the cold areas due to the climate features. This paper is focused on the analysis on the green, low-carbon and energy-saving strategy of the design scheme of gymnasium of Weifang Medical University in cold area in terms of building location, shape design, space organization and technical application.

\section{Brief Introduction to Gymnasium Design}

The design concept is from cell structure so as to discuss the correlation of all functions, structure and environment of building as a cell body from the perspective of biology; dynamic and growing architectural shape is formed by simplifying, extracting and combining such relationship.

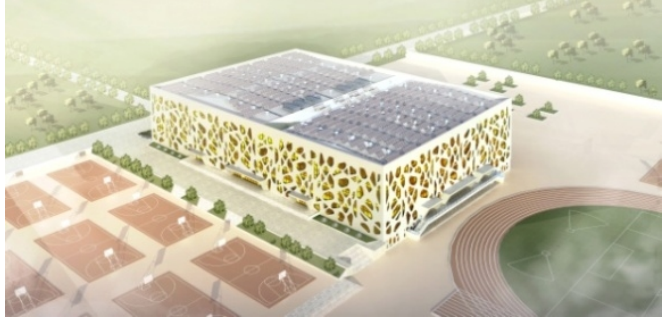

Fig. 1 Aerial View of Gymnasium

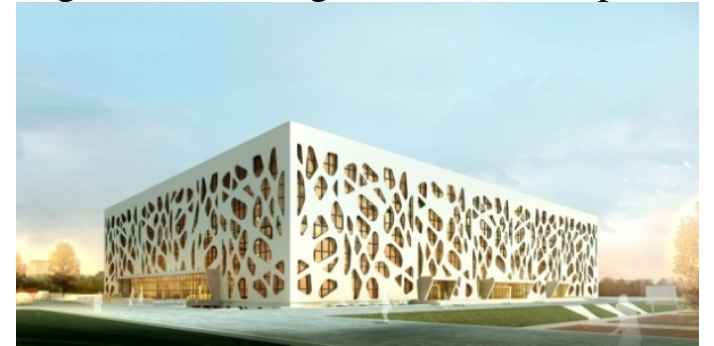

Fig. 2 Perspective Drawing of Gymnasium

Located in the eastern side of the campus, the gymnasium (see Fig. 1 and Fig. 2) covers an area of $7,014.4 \mathrm{~m}^{2}$ with the total building area of $20,778 \mathrm{~m}^{2}$ and building height of $19.8 \mathrm{~m}$. It includes four partial layers above the ground and one underground layer, including basketball arena, tennis hall, table tennis training hall, badminton hall and other sports teaching classrooms and offices.

Analysis on the Application of Green, Low-carbon and Energy-saving Strategy of Gymnasium Several technical measures such as the utilization of solar energy, geothermal energy and water resources, light guide natural guiding, unpowered ventilator and chimney draft (see Fig. 3) should be combined to reach the green building design requirements which can save land, energy, water and materials. The general design strategy shall include the following several aspects: 


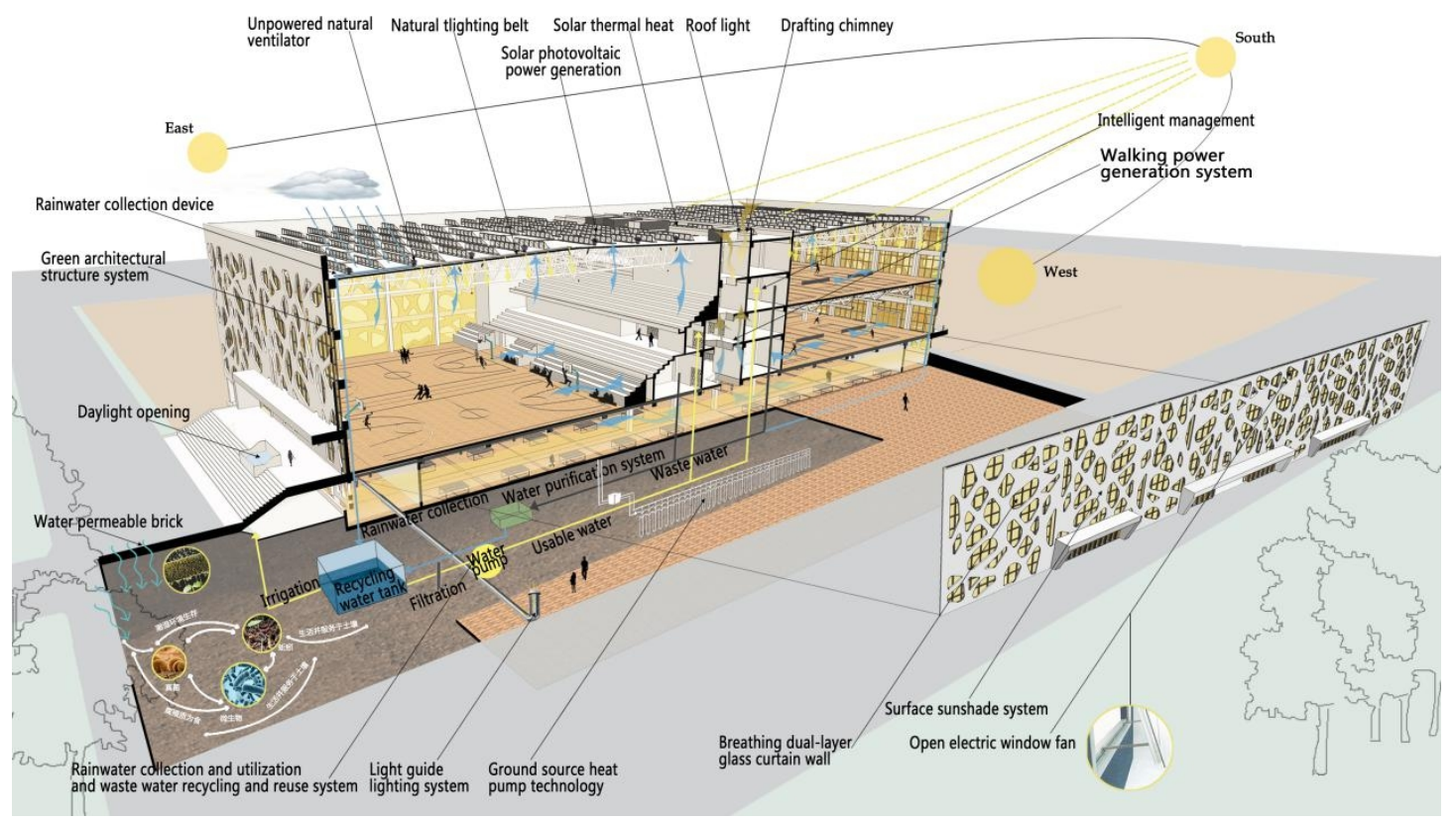

Fig. 3 Schematic Diagram of General Technical Strategy

Location selection of building adaptive to climate. If the gymnasium is located in the southeastern side, it can avoid the prevailing wind direction in winter and protect buildings from losing heat energy. On the contrary, it is in the southeastern prevailing wind direction in summer to help dissipate heat and ventilate and reduce refrigeration energy consumption. Spacious track field is planned at the southern side of the building which can thus enjoy good lighting and solar radiation and better realize heat insulation in winter and ventilation in summer.

Energy-saving of exterior envelope. The building skin of gymnasium consists of dual-layer glass curtain wall in the interior layer and framework aluminum plate with special texture in exterior layer. The spacing of the interior and exterior layer is $20 \mathrm{~cm}$. The design idea of framework aluminum plate texture is from the irregular cell population on biomedicine. Its ecological and energy-saving features include:

Natural lighting. All four building facades are provided with large dual-layer glass curtain walls, which, with the assistance of bar roof light on roofs, satisfies the illumination requirements of training ground in sunny days (see Fig. 4). Framework aluminum plate with special texture is also provided for glass curtain wall since such irregular frame with different openings of holes can serve as sunshade components in summer, avoid isolating warm sunshine in winter and bring more space funs while preventing excessive solar radiation from entering indoors.

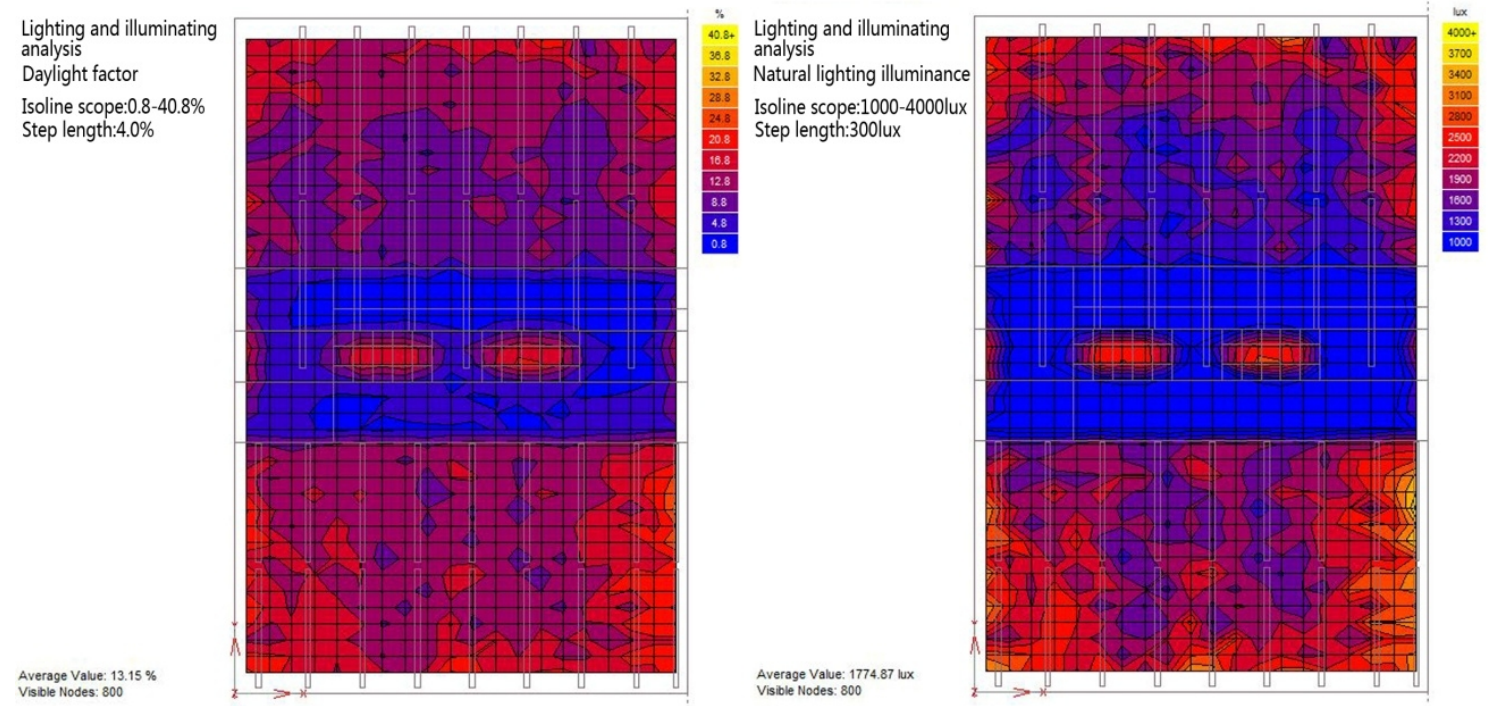

Fig. 4 Analysis on Lighting Simulation of the First Floor 
Insulation. The glass curtain wall of gymnasium is of open inner and outer circulation dual-layer type. The inner curtain wall is closed and provided with hollow glass while the outer curtain wall is provided with single-layer glass and provided with air inlet and outlet. Building envelope is formed by such two layers of glasses, between which, one $300 \mathrm{~mm}$ air interlayer is left. Hot air will be formed indoors if opening air inlet and outlet in summer and "smoke effect" is formed based on the principle of thermal pressure ventilation, to bring the air between glasses to exhaust so as to exchange gas naturally and cool down. If air inlet and outlet are closed in winter, the static air interlayer between dual-layer glasses will play a role in buffering and finally forms greenhouse effect, which can improve the temperature of building internal, help reduce heat energy consumption and improve the quality of air in the gymnasium to a certain extent.

Technical measures for rainwater collection and recycling and reuse of reclaimed water. Both rainwater collection and recycling and treatment and reuse of reclaimed water are considered for the recycling of water resources in the design of gymnasium of Weifang Medical University.

On one hand, the ground bricks on the ground of square in front of main entrances at the eastern and western sides of the gymnasium enjoy good water permeability and the ground rainwater can enter the underground recycling water tank by greening land and seepage. Roof rainwater can also be collected to recycling water tank through down pipe; on the other hand, the washing waste water from the toilet and bathing room of gymnasium can also enter physical sedimentation tank through pipeline and then be recycled to underground recycling water tank after purified, so as to undergo treatment together with rainwater saved through sedimentation and filtration. The water then can be used for campus greening irrigation, bathroom cleaning and vehicle washing.

\section{Utilization of renewable energy.}

Utilization of solar energy. The roof and breast board at the southern building entrance of the building are paved with considerable photovoltaic panel, which does not affect the effect of building facade but can transform solar energy to electricity which can be used for lighting of gymnasium and the corridors of students' apartments nearby. The photovoltaic array of gymnasium roof consists of 1,216 single crystal silicon components with the installation angle of $42^{\circ}$ (based on $+6^{\circ}$, the latitude of Weifang City). The annual power generation quantity is $223,000 \mathrm{kWh}$. Roof solar radiation absorbed by photovoltaic panels will be transformed into electricity, which can reduce the integral roof temperature of gymnasium, roof heat and refrigeration load within gymnasium and thus save energy.

Utilization of geothermal energy. Horizontal pipe embedded GSHP air conditioning system is used in designing gymnasium. In other words, the energy of earth in shallow layer can be used as the heat source in winter and cold source in summer. Based on the water added with anti-freezing solution, the heat pump unit gives cold and hot supplies to buildings. This system is more reliable and stable than the traditional air conditioning system and enjoys dramatic environment benefits. Compared with air source heat pump, it can reduce more than $40 \%$ of pollutants discharged and even $70 \%$ than the common electric air conditioner. It can reduce the emission of carbon dioxide and enjoys low-carbon and environmentally friendly advantages compared with other air conditioning modes.

\section{Conclusion}

In the scheme design, the natural resources are fully utilized by taking advantage of suitable measures through considering the climate conditions and geological environment of Weifang. Attention is paid to the ecological demand of building and people-oriented idea in the whole process, ranging from preliminary location selection and planning to the utilization of ecological energy-saving technique in late stage. The requirements for the rationality, comfort and ecology and energy-saving of the gymnasium should also be satisfied. It does provide valuable reference to the ecological and energy-saving design of university gymnasium in cold areas. 


\section{References}

[1]Huahui Chen. Huazhong Architecture, 2009 (12): 55-56 (In Chinese)

[2] Xiaoxi Cai. Research on Ecological Design of Small and Medium-sized University Gymnasium in the Summer-hot and Winter-cold Area [D]. Hunan University, 2010

[3] Guoxiang Ding. Building Energy Efficiency, 2011(05):29(In Chinese)

[4]Zhongshuang Liu, Shaoyao He, Shaoyao Tang. Chinese and Overseas Architecture.

2013(02):59-61(In Chinese) 